\title{
LAPAROSCOPIC CHOLECYSTECTOMY EXPERIENCE OF 100 CASES AT A TEACHING HOSPITAL OF SINDH
}

\author{
Kheo Ram Dholia, Aijaz A. Memon, M. Saleem Shaikh and \\ Sikandar Ali Shaikh
}

\begin{abstract}
OBJECTIVE: To study the complications, conversion rate and hospital stay during the initial experience with the laparoscopic cholecystectomy.

DESIGN: A case series.

SETTING: Chandka Medical College Hospital, Larkana - Sindh from March 2003 to February 2004.

METHODS: Total 100 patients suffering from symptomatic gallstone disease were admitted for laparoscopic cholecystectomy.

RESULTS: Out of 100 laparoscopic cholecystectomies performed, 85 (85\%) patients were females and $15(15 \%)$ males. Age range was 25 to 70 years. Only $8(8 \%)$ patients were converted to open surgery. Mean operative time was $\mathbf{6 0}$ minutes. Post-operative hospital stay was $\mathbf{2 4}$ to $\mathbf{4 8}$ hours for uncomplicated cases. Post-operative complications included biliary leakage $3 \%$ minor and $1 \%$ major, duodenal perforation $1 \%$ and port site infection $8 \%$.

CONCLUSION: Laparoscopic cholecystectomy is the ideal procedure for gallstone disease. However, the complications and conversion rate can be minimized by the appropriate training and experience.
\end{abstract}

KEY WORDS: Laparoscopy. Cholecystectomy. Complication. Conversion. Hospital.

\section{INTRODUCTION}

Since the beginning of $20^{\text {th }}$ century, laparoscopy was promoted as valuable adjunctive to diagnose the diseases of abdominal pathologies. But, the laparoscopy only became popular after the advent of video laparoscope. First laparoscopic cholecystectomy was performed by Dr. Philippe Mouret in 1987 in Lyon, France ${ }^{1}$. In 1990, first laparoscopic hernia repair was performed, while in 1991, the laparoscopic colectomy, exploration of common bile duct (CBD), adrenalectomy and oesophagectomy were done ${ }^{2}$. The laparoscopic pancreatic resection was done in $1993^{3}$.

In Pakistan, laparoscopic surgery is being done in several public and private hospitals particularly in large cities and teaching institutions. But, in peripheral teaching institutes of Sindh like Chandka Medical College, this approach was started in March 2003.

This newer operative approach for the treatment of gallstone is globally accepted. Thus, the introduction of laparoscope has revolutionized the surgical approach to many intra-abdominal pathologies. In this paper, we present our initial experience with this technique.

\section{PATIENTS AND METHODS}

Chandka Medical College Hospital, Larkana is a 1,200 bedded peripheral teaching hospital of Sindh, catering patients from lower Punjab, Balouchistan and upper Sindh. All 100 patients with gallstone disease were hospitalized through outpatients department.

Detailed history, clinical examination and investigations such as CBC, ESR, Blood Sugar, Blood Urea, Serum Creatinine, Liver Function Tests, HbsAg, HCV antibody, Chest X-ray, ultrasound of upper abdomen especially hepatobiliary system including size of CBD, ECG and cardiac assessment were done. All the patients of gallstone were included except having acute cholecystitis, choledocholithiasis and obstructive jaundice.

Prior to operation an informed consent from all the patients was taken, explaining the risk of conversion to open operation. Patients were kept nil per orally overnight. All the patients were routinely catheterized in the operation theater. Prophylactic antibiotic (Injection Cefotaxime 1G I/V) was administered before induction of anaesthesia, $2^{\text {nd }}$ dose at the end of procedure and $3^{\text {rd }}$ doze after 12 hours in the ward.

Diclofenic suppository of $100 \mathrm{mg}$ was introduced into the rectum after the induction of anaesthesia. In all patients, pneumoperitoneum was created with Verres needle at the infra-umblical site, then, trocar cannula of $10 \mathrm{~mm}$ was introduced through which telescope was inserted to visualize the abdominal cavity. Other three ports were made, one of $10 \mathrm{~mm}$ at epigastrium and two of $5 \mathrm{~mm}$, each on right side of abdomen. Then, further dissection was carried out i.e. identification of cystic duct and artery which were clipped with Liga clip and gall bladder was separated from liver bed with 
the help of diathermy. The gall bladder was extracted through umbilical port after putting in the rubber bag. (Figures I - IV)

FIGURE I: CYSTIC DUCT AND ARTERY

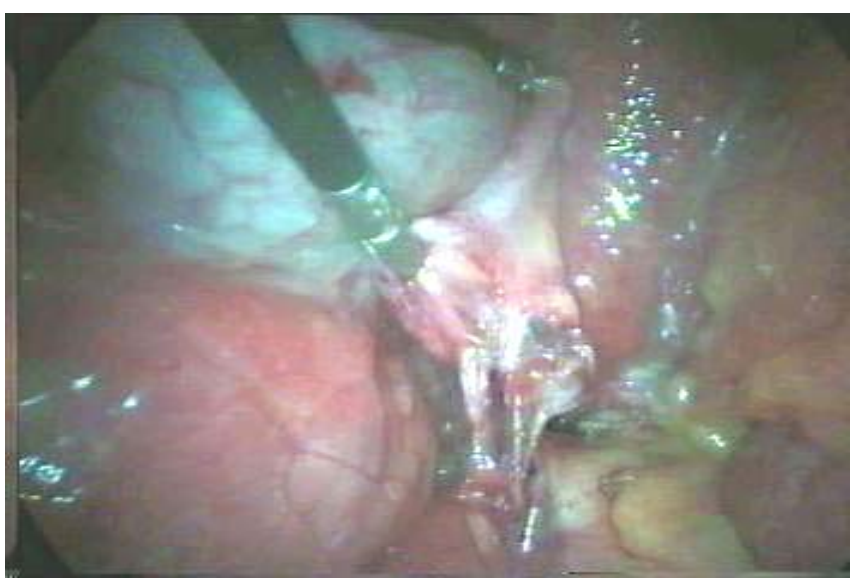

FIGURE II:

LIGA CLIPS APPLIED TO CYSTIC DUCT AND ARTERY

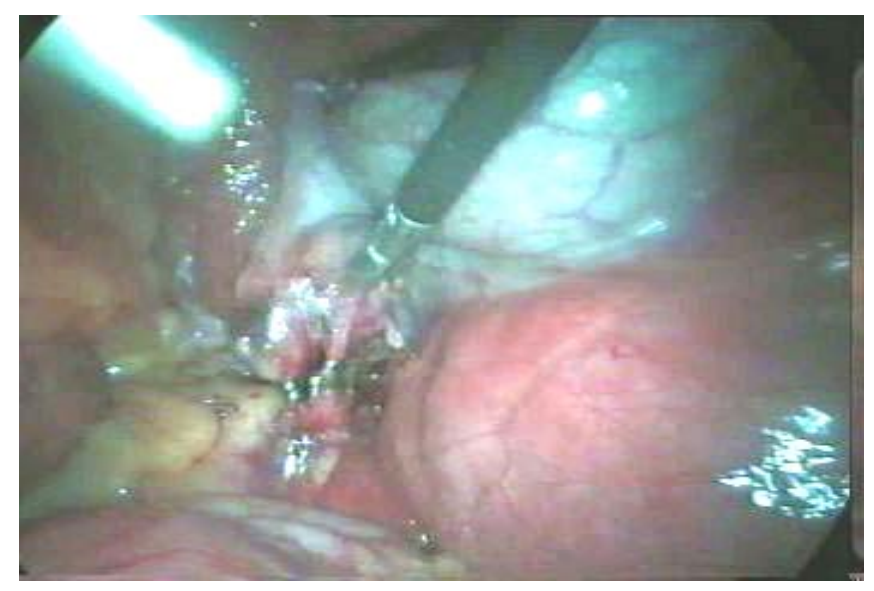

FIGURE III:

GALL BLADDER IS BEING SEPARATED FROM LIVER BED WITH DIATHERMY

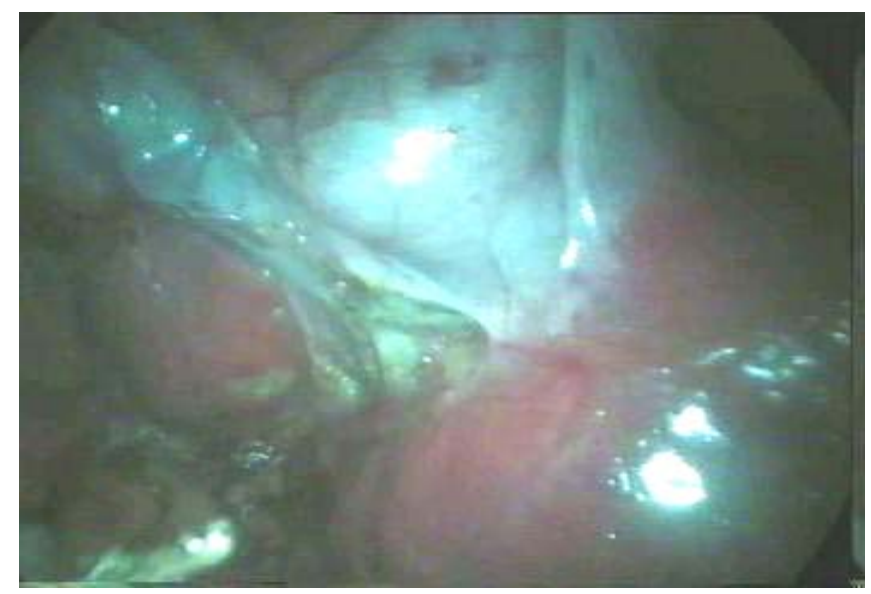

FIGURE IV:

\section{GALL BLADDER IS REMOVED AND PLACED IN RUBBER BAG}

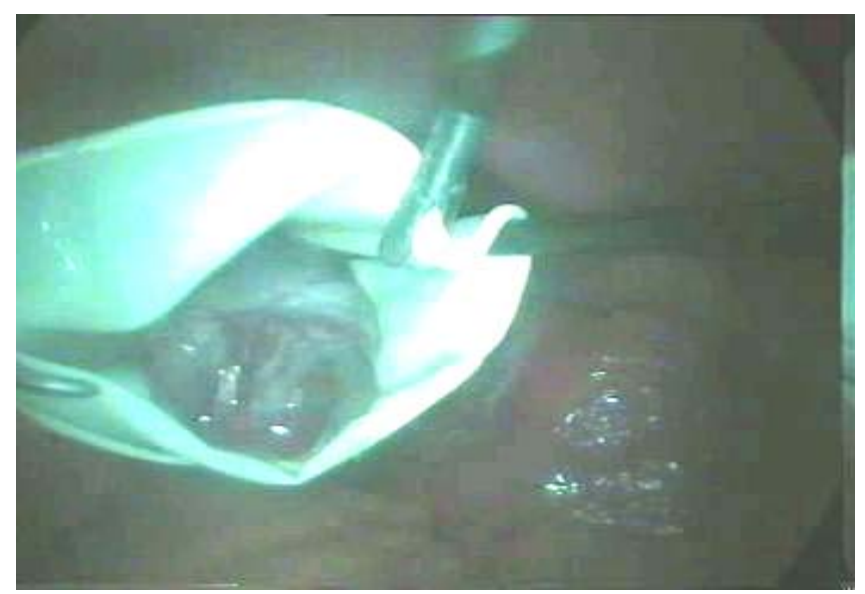

RESULTS

Among 100 cases of laparoscopic cholecystectomy, 85 were females and 15 males with male female ratio of 1:5.6. The age range of patients was 25-70 years with a mean of 42 years. The minimum operative time was 30 minutes while maximum 120 minutes and mean was 60 minutes. Eight patients were converted to open surgery because 4 patients had multiple intraabdominal adhesions due to previous surgery, 2 patients' anatomy was not clear at Calot's triangle, 1 patient had situs inversus and 1 had bleeding from cystic artery. The post-operative hospital stay was 2448 hours for uncomplicated cases, while 5 to 6 days for complicated cases like having injury to common bile duct and duodenal perforation. The post-operative complications were injury to CBD in 1 patient (1\%) and injury to duodenum in 1 patient $(1 \%)$; both required $2^{\text {nd }}$ surgical intervention. Port-site infection was observed in 8 patients (8\%).

TABLE I:

POST-OPERATIVE COMPLICATIONS

\begin{tabular}{|l|c|}
\hline \multicolumn{1}{|c|}{ Complication } & $\begin{array}{c}\text { Number of } \\
\text { patients (\%) }\end{array}$ \\
\hline Biliary leakage & $\begin{array}{l}\text { Minor } \\
\text { Major }\end{array}$ \\
\hline $\begin{array}{l}3(3 \%) \\
1(1 \%)\end{array}$ \\
\hline Duodenal perforation & $1(1 \%)$ \\
\hline $\begin{array}{l}\text { Port site infection } \\
\text { Prolonged post-operative }\end{array}$ & $8(8 \%)$ \\
\hline
\end{tabular}




\section{DISCUSSION}

The gallstone disease is more common in females than males. The advantages of laparoscopic cholecystectomy are well-established and include minimum hospital stay, less pain, minimum scar and less danger of incision hernia. During dissection of cystic artery and cystic duct, it is easier and safe than conventional method mostly in obese patients. In this study, majority of cases belonged to female sex (85\%). This figure is slightly higher than the figures of Jitea $\mathrm{N}$ et $\mathrm{al}^{4}$ (83\% females) and Panpimanmas' et $\mathrm{al}^{5}$ (70.6\% females). Age of patients in this series (mean age of 42 years) is also less than reported by Jitea $\mathrm{N}$ et $\mathrm{al}^{4}(51.2$ years) and comparable to the study of Zuberi et $\mathrm{al}^{6}(42.5$ years). The operative time was 30 minutes to 120 minutes and mean time was 60 minutes which is also less when compared to the findings of Karayiannakis $\mathrm{AJ}$ et $\mathrm{al}^{7}$ (66.4 minutes) and Kakizoe $S$ et $\mathrm{al}^{8}(120$ minutes). The conversion rate was $8 \%$ which is consistent with the finding of Cheema $S$ et $\mathrm{al}^{9}(8.3 \%)$, less than the study of Ferrozzi L et $\mathrm{al}^{10}(21 \%)$ and greater than Uchiyama $\mathrm{K}$ et $\mathrm{al}^{11}(6.4 \%)$. It is also less than the study of Knight JS et $\mathrm{al}^{12}(12 \%)$ and Soomro AH et $\mathrm{al}^{13}$. The reasons for conversion in this study were multiple intraabdominal adhesions, unclear anatomy at Calot's triangle, situs inversus and bleeding from cystic artery. The post-operative hospital stay of uncomplicated cases was 24-48 hours while in complicated cases, it was 5 to 6 days (average 2.2 days). This shows shorter hospital stay than the findings of Jitea $\mathrm{N}$ et $\mathrm{al}^{4}$ (3.8 days) and Hazzan D et $\mathrm{al}^{14}$ (3.4 days). In this study, complications noted were biliary leakage, duodenal perforation, port site infection and prolonged post-operative abdominal pain. Minor biliary leakage was seen in $3 \%$ cases which is higher than the study of Mahatharadol $\mathrm{V}$ et $\mathrm{al}^{15}(0.59 \%)$ and Shamiyeh A et $\mathrm{al}^{16}(0.8 \%)$. Meanwhile, major leak was observed in one case due to injury to CBD which is also comparable to the study of Mahatharadol $\mathrm{V}$ et $\mathrm{al}^{15}$ $(0.59 \%)$ and Shamiyeh A et $\mathrm{al}^{16}(0.8 \%)$. Duodenal perforation was observed in $1 \%$ cases which is higher when compared to the findings of Singh $\mathrm{R}$ et $\mathrm{al}^{17}$ $(0.17 \%)$. Port site infection was present in $10 \%$ patients which is higher than the findings of Sarker $\mathrm{S}$ et $\mathrm{al}^{18}(4.5 \%)$, Ji W et $\mathrm{al}^{19}$, Colizza S et $\mathrm{al}^{20}(6 \%)$. The infection is higher in our initial cases which may be due to improper sterilization of instruments which was improved later resulting in reduced infections. Prolonged post-operative abdominal pain observed in $5 \%$ cases was also slightly more than the figure of Watt-Watson $\mathrm{J}$ et $\mathrm{al}^{21}(4 \%)$.

However, it is concluded from the above discussion that laparoscopic cholecystectomy is the established procedure for the treatment of gall stone disease and the experienced and well-trained team can minimize the post-operative complications and the conversion rate.

\section{REFERENCES}

1. Testas P, Dewatteville JC. Laparoscopic cholecystectomy. Ann Gastroenterol Hepatol (Paris) 1993;29(6):300-6.

2. Kestens PJ, Collard JM, Detry R, et al. Translaparoscopy surgery, a passing fashion or progress?. Bull Mem Acad R Med Belg 1992;147 (6-7):286-7.

3. Patterson EJ, Gagner M, Salky B, et al. Laparoscopic pancreatic resection: singleinstitution experience of 19 patients. J Am Coll Surg 2001;193(3):281-7.

4. Jitea N, Burcos T, Voiculescu S, et al. Analysis of 3100 laparoscopic cholecystectomies. Chirurgia (Bucur) 2001;96(6):553-7. (Roman)

5. Panpimanmas S, Kanyaprasit K. Complications of laparoscopic cholecystectomy and their management. Hepatogastroenterology 2004;51 (55):9-11.

6. Zuberi SJ. Gastrointestinal and biliary tract diseases in Pakistan: a review. J Pak Med Assoc 1983;22:33-36.

7. Karayiannakis AJ, Polychronidis A, Perente S, et al. Laparoscopic cholecystectomy in patients with previous upper or lower abdominal surgery. Surg Endosc 2004;18(1):97-101. Epub 2003 Oct 23.

8. Kakizoe S, Kakizoe Y, Guntani A, et al. Personal experience of laparoscopic cholecystectomy. Hepatogastroenterology 2004;51(58):934-6.

9. Cheema $S$, Brannigan $A E$, Johnson $S$, et al. Timing of laparoscopic cholecystectomy in acute cholecystitis. Ir J Med Sci 2003;172(3):128-31.

10. Ferrozzi L, Lippolis G, Petitti $T$, et al. Laparoscopic cholecystectomy for acute cholecystitis: our experience. G Chir 2004;25 (3):80-2 (Italian).

11. Uchiyama $\mathrm{K}$, Onishi $\mathrm{H}$, Tani $\mathrm{M}$, et al. Timing of laparoscopic cholecystectomy for acute cholecystitis with cholecystolithiasis. Hepatogastroenterology 2004;51(56):346-8.

12. Knight JS, Mercer SJ, Somers SS, et al. Timing of urgent laparoscopic cholecystectomy does not influence conversion rate. $\mathrm{Br} \mathrm{J}$ Surg 2004;91 (5):601-4.

13. Soomro $A H$, et al. Experience of first 100 cases of laparoscopic surgery. J Surg Pak (International) 2002;7(3):47-49.

14. Hazzan D, Geron N, Golijanin D, et al. Laparoscopic cholecystectomy in octogenarians. Surg Endosc 2003;17(5):773-6.

15. Mahatharadol $V$. Bile duct injuries during laparoscopic cholecystectomy: an audit of 1522 
cases. Hepatogastroenterology 2004;51(55):12-4.

16. Shamiyeh A, Wayand W. Laparoscopic cholecystectomy: early and late complications and their treatment. Langenbecks Arch Surg 2004;389(3):164-71. Epub 2004 May 05.

17. Singh R, Kaushik R, Sharma R, et al. Non-biliary mishaps during laparoscopic cholecystectomy. Indian J Gastroenterol 2004;23(2):47-9.

18. Sarker S, Herold K, Creech S, et al. Early and late complications following laparoscopic adjustable gastric banding. Am Surg 2004;70 (2):146-50.
19. Ji W, Li LT, Chen XR, et al. Application of laparoscopic cholecystectomy in patients with cirrhotic portal hypertension. Hepatobiliary Pancreat Dis Int 2004;3(2):270-4.

20. Colizza S, Rossi S, Picardi B, et al. Surgical infections after laparoscopic cholecystectomy: ceftriaxone vs. ceftazidime antibiotic prophylaxis. A prospective study. Chir Ital 2004;56(3):397-402.

21. Watt-Watson J, Chung F, Chan VW, et al. Pain management following discharge after ambulatory same-day surgery. J Nurs Manag 2004;12 (3):153-61.

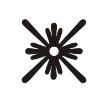

AUTHOR AFFILIATION:

Dr. Kheo Ram Dholia (Corresponding Author)

Assistant Professor of Surgery, Surgical Unit-I, Teaching Hospital,

Chandka Medical College (CMC), Larkana - Sindh.

Dr. Aijaz A. Memon

Associate Professor of Surgery, CMC, Larkana - Sindh.

Dr. M. Saleem Shaikh

Assistant Professor of Surgery, CMC, Larkana - Sindh.

Prof. Sikandar Ali Shaikh,

Head of Department of Surgery, CMC, Larkana - Sindh. 